\title{
Acceptance \& Commitment Therapy: An Overview of Techniques and Applications
}

\author{
Stephen Larmar, Stanislaw Wiatrowski, Stephen Lewis-Driver \\ Griffith School of Human Services and Social Work, Griffith University, Brisbane, Australia \\ Email: s.larmar@griffith.edu.au
}

Received 2 March 2014; revised 1 April 2014; accepted 25 April 2014

Copyright (C) 2014 by authors and Scientific Research Publishing Inc.

This work is licensed under the Creative Commons Attribution International License (CC BY). http://creativecommons.org/licenses/by/4.0/

(c) (i) Open Access

\begin{abstract}
Acceptance and Commitment Therapy (ACT) has emerged over the last twenty years within the context of the Third Wave of Cognitive Therapies, and has been utilised with reported success in a range of therapeutic and mental health settings. Social and self-stigma related to seeking assistance for mental health and other concerns has been shown to reduce client engagement with therapeutic support. Numerous studies have been undertaken that support ACT as an empirically validated framework for engaging stigmatised client groups. This paper provides a review of the key philosophical underpinnings and prominent techniques employed in ACT. Further, the paper highlights the utility of ACT in treating mental illness and other conditions by encouraging therapeutic participation through a use of techniques that inherently reduce the self and social stigma related to psychological disturbance and disability.
\end{abstract}

\section{Keywords}

Acceptance and Commitment Therapy, Stigma, Mental Health, Therapeutic Engagement

\section{Introduction}

While the primary intent of counselling and psychotherapeutic interventions is to provide psychosocial support, the potential stigmatising effects of accessing such support, especially for those suffering from mental health concerns, may prohibit engagement [1]-[4]. The consequences of stigmatisation may include delays in therapeutic outcomes [5], exiting therapy prematurely [6] or choosing not to access treatment [7]. Given the impact of potentially stigmatising attitudes towards counselling, greater consideration is necessary for the facilitation of therapeutic approaches that minimise the effects of stigmatisation and promote widening participation and socially inclusive therapeutic practices. This paper provides an overview of ACT and posits that the underlying philosophy and techniques inherent in the process serve to redress potentially stigmatising effects encountered in

How to cite this paper: Larmar, S., Wiatrowski, S. and Lewis-Driver, S. (2014) Acceptance \& Commitment Therapy: An Overview of Techniques and Applications. Journal of Service Science and Management, 7, 216-221.

http://dx.doi.org/10.4236/jssm.2014.73019 
alternative forms of therapy, thus rendering the ACT approach as a cogent framework to accommodate a diverse population of individuals experiencing mental health concerns.

\section{Acceptance and Commitment Therapy: An Overview}

Developed by Hayes [8] in the late 1980's, ACT emerged from behaviourist approaches to therapy. Behaviour therapy is conceptualized within three corresponding categories or "generations" that include: behaviour therapy; cognitive behavioural therapy (CBT) and the "third generation" or "third wave" of behaviour therapy [9] [10]. ACT is grounded in behaviourism, but is underpinned by analysis of cognitive processes [11]. In light of increasing empirical evidence, attempts have been made to classify ACT in its own right as a distinct, unified model of behaviour change linked to "contextual behavioural science" [12]. This third wave of behaviourism supports openness and acceptance of psychological events, including those that are traditionally perceived to be negative or irrational [13]. The chief purpose of ACT is to encourage individuals to respond to situations constructively, while simultaneously negotiating and accepting challenging cognitive events and corresponding feelings, rather than replacing them. A key feature of ACT is the emphasis on the notion that behaviours and emotions can exist simultaneously and independently. ACT encourages the individual to accept and integrate into their lived experiences challenging affective responses and to recognise and eliminate the controlling dimensions that specific contextual situations exert upon them [9].

ACT is underpinned by functional contextualism [14], a pragmatic philosophical position that recognises that psychological events (encompassing cognition, affective responses and behaviour) are influenced by antecedents within a specific context [15]. According to Hayes [13] the

“... core components of functional contextualism are a) focus on the whole event, $b$ ) sensitivity to the role of context in understanding the nature and function of an event, c) emphasis on a pragmatic truth criterion, and d) specific scientific goals against which to apply the truth criterion".

A reductionist approach to therapy that focuses solely on the analysis of 'dysfunctional' behaviour, rather than placing common behavioural responses within an historical and contextual position is rejected in ACT [13]. The approach utilises relational frame theory (RFT), a behaviour analytic theory of human behaviour that serves to explain the complex interplay of thought processes with behaviours [16] [17]. RFT provides a conceptual framework for understanding “... the learned ability to arbitrarily relate events, mutually and in combination, and to change the functions of events based on these relations" [18]. According to RFT maladaptive processes occur as a result of the individual avoiding "private events" (cognitive processes and affective responses) based on their negative appraisal of these events. As the individual engages in ACT they learn to integrate these private events, consolidate personal values and adopt new ways of behaving [19].

A key assumption of ACT is that psychological processes in most individuals have the potential to be destructive, in contrast to the predominant Western view that fundamentally, humans are psychologically healthy beings [9]. Unlike cognitive-behavioural approaches that reinforce the dynamic interplay between cognition, behaviour and affect and the focus on replacing maladaptive thought processes with healthier cognitions, ACT teaches individuals to "just notice", accept and embrace private experiences and focus on behavioural responses that produce more desirable outcomes [20]. Through this process the individual is encouraged to exercise increased psychological flexibility, drawing on personal values that lead to meaningful action [21].

The acronym FEAR is sometimes utilised in ACT to highlight key variables associated with psychological disequilibrium: Fusion of thoughts; Evaluation of experience; Avoidance of experience; and Reason-giving for behaviour [22]. Inherent in the practice of ACT are a number of mindfulness skills that include:

- Acceptance of thoughts and emotions;

- Cognitive defusion which involves developing accurate awareness of thoughts and emotions;

- Awareness of the moment by being open and receptive; and

- Observation of self [9].

By focusing upon accepting and integrating private events rather than "extinguishing" maladaptive thought patterns, these ACT techniques affectively reduce the self-stigma that often acts as a barrier to client engagement with therapy [4] [23].

\section{Therapeutic Techniques Common to ACT}

ACT approaches to therapy serve to counteract the negative effects of avoiding affective content, the influence 
of dogmatic literal responses to presenting cognitive themes and failure to commit to changes in behaviour [24] [25]. Like cognitive-behavioural therapy the process assists in the facilitation of changes in the individual's internal dialogue or self-talk and their verbal behaviour. The therapist encourages the individual to embrace their feelings, given that denying or struggling with negative affective responses can be counterproductive to psychological health [26]. Initially, the therapist assists the individual to clarify challenges in the individual's world that they can overcome and those that they need to accept as an ongoing part of their lived experience.

According to Hayes [13] seven core processes are inherent in the practice of ACT. These include:

1) Confronting the system - the therapist assists the individual to examine strategies the individual has adopted in an attempt to overcome the presenting problem and to ".. challenge the linguistic set that defines both problems and their solutions, because that set is itself viewed to be a problem" [13]

2) Recognising control as the problem - the therapist helps the individual to understand that in terms of private events (thoughts and feelings) control strategies often may exacerbate the very thoughts and feelings the individual is trying to manage. ACT recognizes that systems of problem-solving are based on socially constructed regulations that are linguistically centred [19]. The therapist helps the individual to see that adhering to such rules can create the source of the individual's problem.

3) Identifying cognitive defusion and mindfulness - the therapist facilitates the process of helping the individual to achieve cognitive defusion as a means of encouraging greater flexibility in behavioural responses. This involves assisting the individual to ameliorate the negative impacts of thoughts, rather than attempting to adapt or replace their content and frequency by reducing the thought's significance.

4) Developing a transcendent sense of self-the therapist engages the individual in experiences that assist the individual to move into a position of personal transcendence as a means of momentarily separating themselves from the challenging experience in order to more objectively explore physical sensations, emotional responses, memories and cognitive patterns.

5) Promoting acceptance and willingness - the therapist assists in the promotion of the individual wholly embracing their experiences in the here and now.

6) Clarifying values - as part of the therapeutic process the therapist encouragers the individual to develop a greater awareness of the values that are important to them as a means of motivating acceptance, willingness and committed action that assists the individual to take control of their lives.

7) Establishing commitment-a culminating process in ACT is the discarding of experiential avoidance and cognitive fusion and the establishment of committed behavioural responses that are congruent with the individual's identified values and that serve to empower them [13].

Eifert and Forsyth [27] encapsulate the key stages inherent in ACT, through the delineation of three distinct therapeutic steps that include:

1) Accepting thoughts and feelings as a means of eliminating the challenges associated with reducing, modifying or rejecting cognitive or affective influences.

2) Choosing future directions that align with the individual's goals and underlying values.

3) Taking action through the process of committing to identified areas of the individual's world that require change.

\section{Effectiveness of ACT: Treatment; Reduction of Stigma; and Increased Therapeutic Engagement}

ACT is gaining international recognition as a therapeutic approach that accommodates a range of individuals and presenting problems [9] [10] [12]. It facilitates an inclusive approach representing an alternative framework of counselling that serves to counteract some of the potentially stigmatising effects of therapeutic approaches for clients with mental illness [4] [28] [29]. The effectiveness of ACT based interventions for individuals with depression, anxiety, specific phobias and a range of other diagnosed mental health concerns has been demonstrated [20] [30]-[38]. Multiple studies highlight the utility of ACT in enabling individuals to more effectively manage diagnosed conditions that are recognised as difficult to treat using other counselling modalities. Key findings emerging from current ACT research indicate that processes foundational to the approach, such as mindfulness, cognitive defusion, the promotion of acceptance and willingness, as well as commitment to change, are conducive to reducing the potentially stigmatising effects of seeking counselling support.

Beyond its usefulness as an efficacious and inclusive therapeutic intervention for mental illness, a growing 
body of research is emerging that highlights the positive impact of ACT in reducing barriers to participation through application to a range of other complex issues including physical, intellectual and psychosocial challenges [22] [39]-[45]. ACT has been shown as an effective treatment approach for assisting individuals in the psychosocial adjustment to pain management and numerous other psychological and physical disabilities. Given the emphasis in approaches such as cognitive-behavioural therapy, on the replacement of maladaptive thought processes as part of the adjustment process in managing disablement, chronic pain or biological precursors of mental illness, individuals seeking counselling may understandably struggle to process inherent, complex thoughts \& entrenched schemas. In contrast, ACT empowers the individual to accept their thought processes as a realistic and necessary function of psychosocial adjustment, therefore normalising their experience and reducing the potentially stigmatising effects associated with negative cognitive schemas. Further, like many forms of disablement, many of the biological precursors of mental health conditions represent permanent states of being, thus many of the techniques used in ACT, such as acceptance, can be cogent in assisting individuals to embrace and integrate the biological features of their condition as part of their core identity.

Research into the effects of ACT for individuals with addictive behaviours and substance abuse also highlights the merits of this approach with this identified population [24] [46] [47]. Individuals experiencing substance abuse and addiction often feel a sense of helplessness in accessing the support necessary to assist them, given the stigma associated with addictive patterns of behaviour and help seeking responses [48] [49]. ACT serves to address the potentially stigmatising effects of counselling on the individual by facilitating a process where the individual can learn to accept themselves, in spite of their addictive behaviours and negotiate a commitment to change based on achievable outcomes. The overall benefits of adopting ACT for populations vulnerable to social stigma are significant. Such an approach is pivotal to the elimination of potential barriers to engagement in counselling and psychotherapy practice.

\section{Conclusion}

This paper has provided an overview of Acceptance and Commitment Therapy (ACT) as a counselling approach that extends upon traditional forms of behaviour therapy. The paper examined the philosophical assumptions foundational to ACT and highlighted techniques and processes common to the approach as a means of summarising the therapeutic framework for ACT as it applies to mental health concerns and a range of other presenting problems. A summary of empirical studies was presented identifying the validity and utility of ACT across a range of contexts for a diverse population of client groups. Finally, discussion centred upon the significance of ACT techniques in eliminating barriers to therapeutic participation and challenging the potentially stigmatizing effects of more traditional approaches to therapy.

\section{References}

[1] Corrigan, P.W. (1998) The Impact of Stigma on Severe Mental Illness. Cognitive and Behavioral Practice, 5, $201-222$. http://dx.doi.org/10.1016/S1077-7229(98)80006-0

[2] Corrigan, P.W. (2004) How Stigma Interferes with Mental Health Care. American Psychologist, 59, 614-625. http://dx.doi.org/10.1037/0003-066X.59.7.614

[3] Clement, S., Schauman, O., Graham, T., Maggioni, F., Evans-Lacko, S., Bezborodovs, N., et al. (2014) What Is the Impact of Mental Health-Related Stigma on Help-Seeking? A Systematic Review of Quantitative and Qualitative Studies. Psychological Medicine, 1-17. http://dx.doi.org/10.1017/S0033291714000129

[4] Vogel, D.L., Wade, N.G. and Hackler, A.H. (2007) Perceived Public Stigma and the Willingness to Seek Counseling: The Mediating Roles of Self-Stigma and Attitudes Toward Counselling. Journal of Counselling Psychology, 54, 40-50. http://dx.doi.org/10.1037/0022-0167.54.1.40

[5] Starr, S., Campbell, L.R. and Herrick, C.A. (2002) Factors Affecting use of the Mental Health System by Rural Children. Issues in Mental Health Nursing, 23, 291-304. http://dx.doi.org/10.1080/016128402753543027

[6] Sirey, J.A., Bruce, M.L., Alexpoulos, G.S., Perokic, D.A., Raue, P., Friedman, S.T., et al. (2001) Perceived Stigma as a Predictor of Treatment Discontinuation in Young and Older Outpatients with Depression. The American Journal of Psychiatry, 158, 479-481. http://dx.doi.org/10.1176/appi.ajp.158.3.479

[7] Kushner, M.G. and Sher, K.J. (1991) The Relation of Treatment Fearfulness and Psychological Service Utilization: An Overview. Professional Psychology: Research and Practice, 22, 196-203. http://dx.doi.org/10.1037/0735-7028.22.3.196 
[8] Hayes, S.C. (1987) A Contextual Approach to Therapeutic Change. In: Jacobson, N., Ed., Psychotherapists in Clinical Practice: Cognitive and Behavioral Perspectives, Guilford, New York, 327-387.

[9] Harris, R. (2006) Embracing Your Demons: An Overview of Acceptance and Commitment Therapy. Psychotherapy in Australia, 12, 2-8.

[10] Hayes, S.C. (2005) Stability and Change in Cognitive Behavior Therapy: Considering the Implications of ACT and RFT. Journal of Rational-Emotive \& Cognitive Behavior Therapy, 23, 131-151. http://dx.doi.org/10.1007/s10942-005-0007-9

[11] Hayes, S.C., Barnes-Holmes, D. and Roche, B. (Eds.) (2001) Relational Frame Theory: A Post-Skinnerian Account of Human Language and Cognition. Plenum Press, New York.

[12] Hayes, S.C., Levin, M.E., Plumb-Vilardaga, J., Villatte, J.L. and Pistorello, J. (2013) Acceptance and Commitment Therapy and Contextual Behavioral Science: Examining the Progress of a Distinctive Model of Behavioral and Cognitive Therapy. Behavior Therapy, 44, 180-196. http://dx.doi.org/10.1016/j.beth.2009.08.002

[13] Hayes, S.C. (2004) Acceptance and Commitment Therapy, Relational Frame Theory, and the Third Wave of Behavioral and Cognitive Therapies. Behavior Therapy, 35, 639-665. http://dx.doi.org/10.1016/S0005-7894(04)80013-3

[14] Biglan, A. and Hayes, S.C. (1996) Should the Behavioral Sciences Become more Pragmatic? The Case for Functional Contextualism in Research on Human Behavior. Applied and Preventative Psychology: Current Scientific Perspectives, 5, 47-57. http://dx.doi.org/10.1016/S0962-1849(96)80026-6

[15] Hayes, S.C. (1993) Analytic Goals and the Varieties of Scientific Contextualism. In Hayes, S.C., Hayes, L.J., Reese, H.W. and Sarbin, T.R., Eds., Varieties of Scientific Contextualism, Context Press, Reno, 11-27.

[16] Neukrug, E.S. (2011) Counseling Theory and Practice. Brooks/Cole, Boston.

[17] Robb, H. (2007) Values as Leading Principles in Acceptance and Commitment Therapy. International Journal of Behavioral Consultation and Therapy, 3, 118-123.

[18] Hayes, S.C., Luoma, J.B., Bond, F.W., Masuda, A. and Lillis, J. (2006) Acceptance and Commitment Therapy: Models, Processes and Outcomes. Behavior Research and Therapy, 44, 1-25. http://dx.doi.org/10.1016/j.brat.2005.06.006

[19] Dewane, C. (2008) The ABCs of ACT: Acceptance and Commitment Therapy. Social Work Today, 8, 36.

[20] Bach, P. and Hayes, S. (2002) The Use of Acceptance and Commitment Therapy to Prevent the Rehospitalization of Psychotic Patients: A Randomized Controlled Trial. Journal of Consulting and Clinical Psychology, 70, 1129-1139. http://dx.doi.org/10.1037/0022-006X.70.5.1129

[21] Zettle, R.D. (2005) The Evolution of a Contextual Approach to Therapy: From Comprehensive Distancing to ACT. International Journal of Behavioral Consultation and Therapy, 1, 77-89.

[22] Takahashi, M., Muto, T., Tada, M. and Sugiyama, M. (2002) Acceptance Rationale and Increasing Pain Tolerance: Acceptance-Based and FEAR-Based Practice. Japanese Journal of Behavior Therapy, 28, 35-46.

[23] Vogel, D.L., Wade, N.G. and Haake, S. (2006) Measuring the Self Stigma Associated with Seeking Psychological Help. Journal of Counseling Psychology, 53, 325-337. http://dx.doi.org/10.1037/0022-0167.53.3.325

[24] Hayes, S.C., Wilson, K.G., Gifford, E.V., Bisset, R., Piasecki, M., Batten, S.V., Byrd, M. and Gregg, J. (2004) A Preliminary Trial of Twelve-Step Facilitation and Acceptance and Commitment Therapy with Polysubstance-Abusing Methadone-Maintained Opiate Addicts. Behavior Therapy, 35, 667-688. http://dx.doi.org/10.1016/S0005-7894(04)80014-5

[25] Zettle, R.D. and Hayes, S.C. (1986) Dysfunctional Control by Client Verbal Behavior: The Context of Reason Giving. Analysis of Verbal Behavior, 4, 30-38.

[26] Hayes, S.C. and Wilson, K.G. (1994) Acceptance and Commitment Therapy: Altering the Verbal Support for Experiential Avoidance. The Behavior Analyst, 17, 289-303.

[27] Eifert, G.H. and Forsyth, J.P. (2005) Acceptance and Commitment Therapy for Anxiety Disorders. New Harbinger Publications Inc., Oakland.

[28] Cooper, A.E., Corrigan, P.W. and Watson, A.C. (2003) Mental Illness Stigma and Care Seeking. Journal of Nervous and Mental Disease, 191, 339-341. http://dx.doi.org/10.1097/01.NMD.0000066157.47101.22

[29] Sibicky, M. and Dovidio, J.F. (1986) Stigma of Psychological Therapy: Stereotypes, Interpersonal Reactions, and the Self-Fulfilling Prophecy. Journal of Counseling Psychology, 33, 148-154. http://dx.doi.org/10.1037/0022-0167.33.2.148

[30] Dalrymple, K.L. and Herbert, J.D. (2007) Acceptance and Commitment Therapy for Generalized Social Anxiety Disorder: A Pilot Study. Behavior Modification, 31, 543-568. http://dx.doi.org/10.1177/0145445507302037

[31] Forman, E.M., Herbert, J., Moitra, E., Yeomans, P. and Geller, P. (2007) A Randomized Controlled Effectiveness Trial of Acceptance and Commitment Therapy and Cognitive Therapy for Anxiety and Depression. Behavior Modification, 31, 772-799. http://dx.doi.org/10.1177/0145445507302202 
[32] Gaudiano, B.A. and Herbert, J.D. (2006) Acute Treatment of Inpatients with Psychotic Symptoms Using Acceptance and Commitment Therapy: Pilot Results. Behavior Research and Therapy, 44, 415-437. http://dx.doi.org/10.1016/j.brat.2005.02.007

[33] Gratz, K.L. and Gunderson, J.G. (2006) Preliminary Data on an Acceptance-Based Emotion Regulation Group Intervention for Deliberate Self-Harm among Women with Borderline Personality Disorder. Behavior Therapy, 37, 25-35.

[34] Ossman, W.A., Wilson, K.G., Storaasli, R.D. and McNeill, J.W. (2006) A Preliminary Investigation of the use of Acceptance and Commitment Therapy in Group Treatment for Social Phobia. International Journal of Psychology and Psychological Therapy, 6, 397-416.

[35] Roemer, L. and Orsillo, S.M. (2007) An Open Trial of an Acceptance-Based Behavior Therapy for Generalized Anxiety Disorder. Behavior Therapy, 38, 72-85. http://dx.doi.org/10.1016/j.beth.2006.04.004

[36] Twohig, M.P. and Woods, D.W. (2004) A Preliminary Investigation of Acceptance and Commitment Therapy and Habit Reversal as a Treatment for Trichotillomania. Behavior Therapy, 35, 803-820. http://dx.doi.org/10.1016/S0005-7894(04)80021-2

[37] Woods, D.W., Wetterneck, C.T. and Flessner, C.A. (2006) A Controlled Evaluation of Acceptance and Commitment Therapy Plus Habit Reversal for Trichotillomania. Behavior Research and Therapy, 44, 639-656. http://dx.doi.org/10.1016/j.brat.2005.05.006

[38] Zettle, R.D. (2003) Acceptance and Commitment Therapy (ACT) vs Systematic Desensitization in Treatment of Mathematics Anxiety. The Psychological Record, 53, 197-215.

[39] Dahl, J., Wilson, K.G. and Nilsson, A. (2004) Acceptance and Commitment Therapy and the Treatment of Persons at Risk for Long-Term Disability Resulting from Stress and Pain Symptoms: A Preliminary Randomized Trial. Behavior Therapy, 35, 785-801. http://dx.doi.org/10.1016/S0005-7894(04)80020-0

[40] Gutierrez, O., Luciano, C., Rodriguez, M. and Fink, B.C. (2004) Comparison between an Acceptance-Based and a Cognitive-Control-Based Protocol for Coping with Pain. Behavior Therapy, 35, 767-784. http://dx.doi.org/10.1016/S0005-7894(04)80019-4

[41] Hayes, S.C., Bissett, R.T., Korn, Z., Zettle, R.D., Rosenfarb, I.S., Cooper, L.D., et al. (1999) The Impact of Acceptance versus Control Rationales on Pain Tolerance. The Psychological Record, 49, 33-47.

[42] Lundgren, T. and Dahl, J. (2005) Development and Evaluation of an Integrative Health Model in Treatment of Epilepsy: A Randomized Controlled Trial Investigating the Effects of Short-term ACT Intervention Compared to Attention Control in South Africa. Association for Behavior Analysis, Chicago.

[43] Lundgren, T., Dahl, J., Melin, L. and Kies, B. (2006) Evaluation of Acceptance and Commitment Therapy for Drug Refractory Epilepsy: A Randomized Controlled Trial in South Africa: A Pilot Study. Epilepsia, 47, 2173-2179. http://dx.doi.org/10.1111/j.1528-1167.2006.00892.x

[44] McCracken, L.M., Vowles, K.E. and Eccleston, C. (2005) Acceptance-Based Treatment for Persons with Complex, Long Standing Chronic Pain: A Preliminary Analysis of Treatment Outcome in Comparison to a Waiting Phase. Behavior Research and Therapy, 43, 1335-1346. http://dx.doi.org/10.1016/j.brat.2004.10.003

[45] Reeve, D. (2000) Oppression within the Counseling Room. Disability and Society, 15, 669-682. http://dx.doi.org/10.1080/09687590050058242

[46] Gifford, E.V., Kohlenberg, B.S., Hayes, S.C., Antonuccio, D.O., Piasecki, M.M., Rasmussen-Hall, M.L. and Palm, K.M. (2004) Acceptance-Based Treatment for Smoking Cessation. Behavior Therapy, 35, 689-705. http://dx.doi.org/10.1016/S0005-7894(04)80015-7

[47] Twohig, M.P., Shoenberger, D. and Hayes, S.C. (2007) A Preliminary Investigation of Acceptance and Commitment Therapy as a Treatment for Marijuana Dependence in Adults. Journal of Applied Behavior Analysis, 40, 619-632. http://dx.doi.org/10.1901/jaba.2007.619-632

[48] Luoma, J.B., Kohlenberg, B.S., Hayes, S.C., Bunting, K. and Rye, A.K. (2008) Reducing Self-Stigma in Substance Abuse through Acceptance and Commitment Therapy: Model, Manual Development, and Pilot Outcomes. Addiction Research and Theory, 16, 149-165. http://dx.doi.org/10.1080/16066350701850295

[49] Luoma, J.B., Twohig, M.P., Waltz, T., Hayes, S.C., Roget, N., Padilla, M. and Fisher, G. (2007) An Investigation of Stigma in Individuals Receiving Treatment for Substance Abuse. Addictive Behaviors, 32, 1331-1346. http://dx.doi.org/10.1016/j.addbeh.2006.09.008 
Scientific Research Publishing (SCIRP) is one of the largest Open Access journal publishers. It is currently publishing more than 200 open access, online, peer-reviewed journals covering a wide range of academic disciplines. SCIRP serves the worldwide academic communities and contributes to the progress and application of science with its publication.

Other selected journals from SCIRP are listed as below. Submit your manuscript to us via either submit@scirp.org or Online Submission Portal.
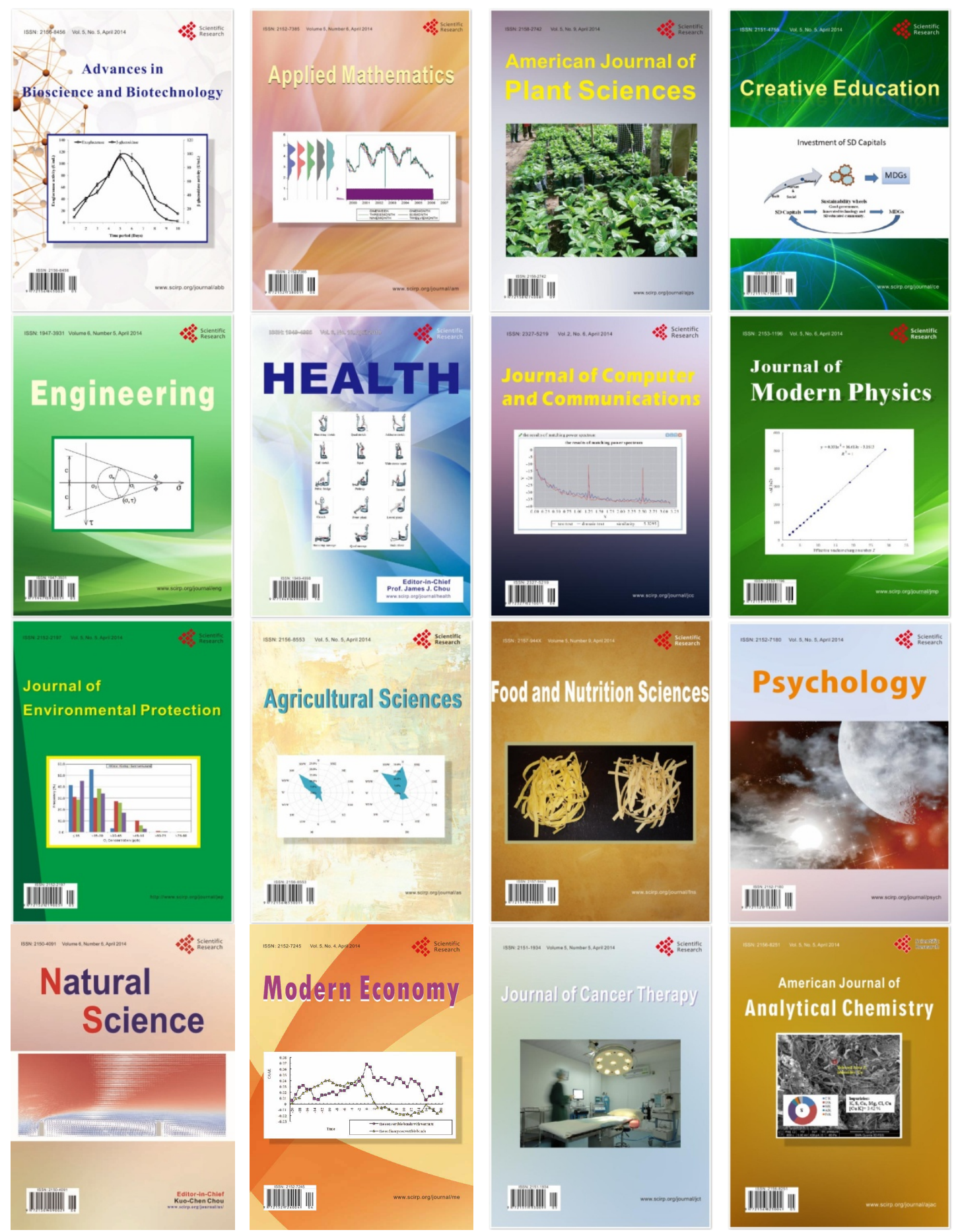